\title{
Synthesis and electrochemical properties of porous tubular TiN powders prepared via ammonia reduction nitridation of nonhydrolytic $\mathrm{TiO}_{2}$ powders
}

\author{
Li-Fang ZHANG ${ }^{*, *, * * *}$, Jing-Long BU ${ }^{* *, \dagger}$, Heng-Yong WEI ${ }^{* *}$, Min $\mathrm{CHEN}^{*, *}$, \\ Hui-Xing LIU**, Jie NI* and Dong-Feng LV $^{* *}$ \\ ${ }^{*}$ School of Metallurgy, Northeastern University, Shenyang 110819, China \\ ${ }^{* *}$ College of Materials Science and Engineering, Hebei Provincial Key Laboratory of Inorganic Nonmetallic Materials, \\ North China University of Science and Technology, Tangshan 063009, China \\ **** Qinggong College, North China University of Science and Technology, Tangshan Key Laboratory of Functional Envirnmental \\ Materials, Tangshan 063000, China
}

\begin{abstract}
Porous tubular $\mathrm{TiO}_{2}$ powders were prepared first via a novel facile and non-template route of the nonhydrolytic sol-gel method. The as-prepared $\mathrm{TiO}_{2}$ powders could then be directly converted into porous tubular $\mathrm{TiN}$ powders through an ammonia reduction nitridation process. The results indicated that the obtained $\mathrm{TiO}_{2}$ powders consisted of a pure, well-crystallized anatase $\mathrm{TiO}_{2}$ phase of porous tubular morphology, with a Brunauer-Emmett-Teller (BET) specific surface area of $39 \mathrm{~m}^{2} / \mathrm{g}$ and an average pore size of $11 \mathrm{~nm}$ and pore volume of $0.012 \mathrm{~cm}^{3} / \mathrm{g}$. After the porous tubular $\mathrm{TiO}_{2}$ powders were calcined at $800^{\circ} \mathrm{C}$ for $2 \mathrm{~h}$ under an ammonia $\left(\mathrm{NH}_{3}\right)$ gas atmosphere, TiN powders maintaining their porous tubular architecture were obtained, with a BET specific surface area of $35 \mathrm{~m}^{2} / \mathrm{g}$ and an average pore size and pore volume of $12 \mathrm{~nm}$ and $0.096 \mathrm{~cm}^{3} / \mathrm{g}$, respectively. The electrochemical performance of the porous tubular TiN powders demonstrated that TiN powders could be a promising electrode material for supercapacitors.
\end{abstract}

(C2017 The Ceramic Society of Japan. All rights reserved.

Key-words : Tubular TiN, Porous, Nonhydrolytic sol-gel, Ammonia reduction nitridation, Ethanol

[Received April 4, 2017; Accepted June 5, 2017]

\section{Introduction}

Titanium nitride (TiN) materials possess such excellent properties as super-hardness, corrosion resistance, high electrical/thermal conductivity, and chemical/thermal stability. ${ }^{1)-3)}$ They are therefore widely applied as catalysts and catalystsupport materials in dye-sensitized solar cells, ${ }^{4)-6)}$ fuel cells, batteries, ${ }^{7)-12)}$ and supercapacitors. ${ }^{13)-15)}$ Particular attention is being paid to powders with porous architectures due to their high surface-to-volume ratios, which could improve the permeability and charge transport for distinctive physicochemical properties. ${ }^{16)}$ Special interest has developed, moreover, in controlling synthetic approaches to porous and tubular TiN materials. Liu et al. synthesized hierarchical nanotubular TiN by magnesiothermic reduction of $\mathrm{TiO}_{2}$ replicas of a cellulose substance (filter paper) in $\mathrm{N}_{2},{ }^{17)}$ for example, Xie et al. prepared TiN nanotubes by an anodization process of $\mathrm{TiO}_{2}$ in ethylene glycol solution, and a subsequent nitridation process in an $\mathrm{NH}_{3}$ gas atmosphere. ${ }^{18)}$ However, these approaches generally require a complicated and long-term fabrication process to prepare $\mathrm{TiO}_{2}$ precursors. Thus, it is more efficient to prepare $\mathrm{TiO}_{2}$ precursors with various ultrastructures by exploring facile, easily controlled and lower-cost synthetic routes.

Recently, a novel simple and template-free technique, the nonhydrolytic sol-gel method, has been developed to prepare $\mathrm{TiO}_{2}$ materials with versatile morphologies. ${ }^{19)-22}$ The use of anhydrous ethanol as the oxygen donor, in particular, contributes

Corresponding author: J. L. Bu; E-mail: bj11957@126.com

* Corresponding author: M. Chen; E-mail: chenm@smm.neu.edu.cn to the formation of tubular $\mathrm{TiO}_{2}$ materials. ${ }^{22), 23)}$ However, there are lower reports on synthesis of porous tubular TiN powders using an ammonia reduction nitridation process based on the nonhydrolytic sol-gel method.

In this paper, we describe a new route to synthesis of porous tubular TiN powders via ammonia reduction nitridation of nonhydrolytic $\mathrm{TiO}_{2}$ powders using ethanol as an oxygen donor. It is demonstrated that porous tubular structured TiN powders can be proposed as a promising electrode material for supercapacitors.

\section{Experimental}

\subsection{Sample preparation}

The following reactants were used for the synthesis of $\mathrm{TiO}_{2}$ powders: titanium tetrachloride $\left(\mathrm{TiCl}_{4}\right)$ as a titanium resource, anhydrous ethanol $\left(\mathrm{C}_{2} \mathrm{H}_{5} \mathrm{OH}\right)$ as an oxygen donor and dichloromethane $\left(\mathrm{CH}_{2} \mathrm{Cl}_{2}\right)$ as a solvent. All chemicals were used as received without further purification. Porous tubular $\mathrm{TiO}_{2}$ powders were prepared by the nonhydrolytic sol-gel method. First, $8.8 \mathrm{~mL}$ of $\mathrm{TiCl}_{4}$ and $30 \mathrm{~mL}$ of $\mathrm{CH}_{2} \mathrm{Cl}_{2}$, respectively, were added slowly to $9.3 \mathrm{~mL}$ of $\mathrm{C}_{2} \mathrm{H}_{5} \mathrm{OH}$ solution under vigorous stirring at room temperature. The obtained mixture was heated in an autoclave at $110^{\circ} \mathrm{C}$ for $38 \mathrm{~h}$ to form $\mathrm{TiO}_{2}$ gelations (gels). Second, the gels were dried at $80^{\circ} \mathrm{C}$ in air and then calcined to obtain $\mathrm{TiO}_{2}$ powders at a heating rate of $5^{\circ} \mathrm{C} / \mathrm{min}$ to $600^{\circ} \mathrm{C}$ for $30 \mathrm{~min}$. The as-prepared $\mathrm{TiO}_{2}$ powders were then placed in the quartz boat reactor of a tube furnace. The reduction nitridation of the $\mathrm{TiO}_{2}$ powders proceeded as follows: the furnace was flushed with $\mathrm{N}_{2}$ gas at a flow rate of $100 \mathrm{~mL} / \mathrm{min}$ for $30 \mathrm{~min}$ to remove $\mathrm{O}_{2}$ at room temperature. The $\mathrm{N}_{2}$ gas was then replaced with dry $\mathrm{NH}_{3}$ 
gas. The flow rate of $\mathrm{NH}_{3}$ gas was kept at about $400 \mathrm{~mL} / \mathrm{min}$ at 300 to $500^{\circ} \mathrm{C}$. When the temperature reached $500^{\circ} \mathrm{C}$, the flow rate of $\mathrm{NH}_{3}$ gas was adjusted to $800 \mathrm{~mL} / \mathrm{min}$ up to $800^{\circ} \mathrm{C}$ and then held there for $2 \mathrm{~h}$. During the furnace cool down, the same nitridation gas flow rate procedure was applied with a corresponding elevating temperature process. Finally, TiN powders were obtained.

\subsection{Characterization techniques}

The X-ray diffraction (XRD) patterns of the samples were recorded with a Rigaku X-ray diffractometer (D/MAX2500PC, Japan) using a $\mathrm{Cu}-\mathrm{K}_{\alpha}$ with radiation from 10 to $80^{\circ}$ at a scanning speed of $10^{\circ} \mathrm{C} / \mathrm{min}$. The morphological structure of the synthesized TiN material was observed by scanning electron microscopy (SEM, S-4800, Japan). The specific surface area was measured using a Brunauer-Emmett-Teller (BET) technique (Quantachrome Inst., NOVA2200e). And the Barrett-Joyner-Halenda (BJH) model was used for determining the pore diameter distribution of the synthesized TiN material.

As the battery testing system, a LIR2032 button-type supercapacitor was employed to study the electrochemical performance of the porous tubular TiN powders. The TiN powders as the active material were mixed with acetylene black and PVDF (wt \%, 16:3:1, respectively). The mixed samples were pasted on nickel foam, dried at $80^{\circ} \mathrm{C}$ for $24 \mathrm{~h}$, and formed under a pressure of $10 \mathrm{MPa}$. A LIR2032 button-type supercapacitor was then assembled using two identical TiN electrodes, $1 \mathrm{M} \mathrm{Na}_{2} \mathrm{SO}_{4}$ as an aqueous electrolyte and polypropylene as the diaphragm. The cyclic voltammetry $(\mathrm{CV})$ and electrochemical impedance spectroscopy (EIS) measurements of the TiN material were evaluated using an electrochemical workstation instrument (CHI Instrument Inc., CHI604E). And galvanostatic charge/discharge (GCD) testing was performed with a battery-testing system (LAND Instrument Inc., CT2001A).

\section{Results and discussion}

\subsection{Characterization of nonhydrolytic $\mathrm{TiO}_{2}$ powders}

XRD patterns of as-prepared nonhydrolytic $\mathrm{TiO}_{2}$ gels after calcination at $600^{\circ} \mathrm{C}$ for $30 \mathrm{~min}$ are shown in Fig. 1. These indicate that pure anatase $\mathrm{TiO}_{2}$ is formed in the powders. No trace of rutile is detected. Anatase phase $\mathrm{TiO}_{2}$ favors further reduction nitridation of as-prepared $\mathrm{TiO}_{2}$ powders. ${ }^{24}$

In our experiment, when $\mathrm{TiCl}_{4}$ was added to $\mathrm{a}_{2} \mathrm{H}_{5} \mathrm{OH}$ solution at room temperature, it interacts first with the $\mathrm{C}_{2} \mathrm{H}_{5} \mathrm{OH}$ to produce titanium alkoxide $\mathrm{TiCl}_{2}(\mathrm{OR})_{2}\left(\mathrm{R}=\mathrm{CH}_{2} \mathrm{CH}_{3}\right)$ with the liberation of $\mathrm{HCl}^{24)}$ The corresponding reaction can be written as:

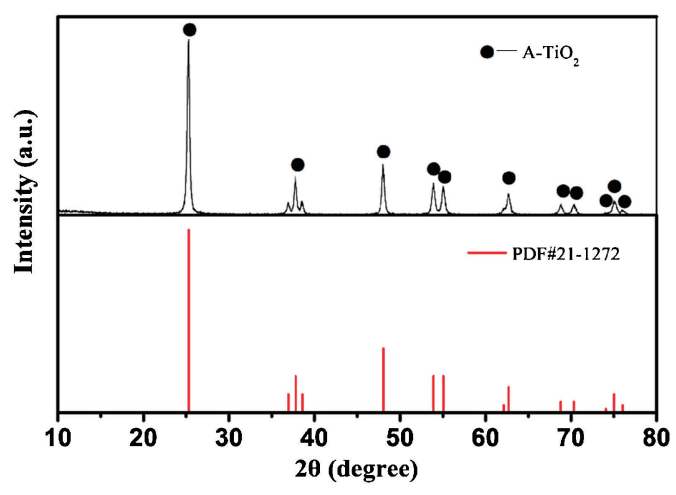

Fig. 1. XRD patterns of as-prepared $\mathrm{TiO}_{2}$ powders.

$$
\mathrm{TiCl}_{4}+2 \mathrm{ROH} \rightarrow \mathrm{TiCl}_{2}(\mathrm{OR})_{2}+2 \mathrm{HCl}
$$

The nonhydrolytic nucleophilic substitution reaction among the titanium alkoxide $\mathrm{TiCl}_{2}(\mathrm{OR})_{2}$ precursors to form titanium gels can be written as:

$$
\begin{aligned}
& \mathrm{ORCl}_{2} \mathrm{Ti}-\mathrm{OR}+\mathrm{Cl}-\mathrm{Ti}-(\mathrm{OR})_{2} \mathrm{Cl} \\
& \quad \rightarrow \mathrm{ORCl}_{2} \mathrm{Ti}-\mathrm{O}-\mathrm{Ti}(\mathrm{OR})_{2} \mathrm{Cl}+2 \mathrm{RCl}
\end{aligned}
$$

The microstructure of as-prepared nonhydrolytic $\mathrm{TiO}_{2}$ powders was characterized by SEM imaging as shown in Fig. 2. It was found that anatase $\mathrm{TiO}_{2}$ crystals grow mainly into tubular clusterlike structures in the SEM image at high magnification (inset). As explained by other reports in the literature, ${ }^{25)}$ the dramatic change in crystal morphology can be explained based on selective interaction of the solvents with surface ions, which exhibits the growth of specific lattice planes and thus results in the expression of these lattice planes in the final crystal form. The resultant morphologies of nonhydrolytic $\mathrm{TiO}_{2}$ products could have an inherent relation with the chelate precursors between $\mathrm{TiCl}_{4}$ and $\mathrm{C}_{2} \mathrm{H}_{5} \mathrm{OH} .{ }^{24)}$

SEM images at high magnification revealed that a number of pores were also formed on the surface of tubular $\mathrm{TiO}_{2}$, and quantities of tubular $\mathrm{TiO}_{2}$ were also formed. The average inner diameter of tubular $\mathrm{TiO}_{2}$ was about $350 \mathrm{~nm}$ and the length was approximately $1.5 \mu \mathrm{m}$.

The results of the investigation of the surface area, pore size, and the BET surface area of nonhydrolytic $\mathrm{TiO}_{2}$ powders were recorded as shown in Fig. 3. The $\mathrm{N}_{2}$ adsorption-desorption curves of $\mathrm{TiO}_{2}$ powders showed a Type IV isotherm characteristic of mesoporous materials, ${ }^{26)}$ featuring an $\mathrm{H} 2$ hysteresis loop. ${ }^{27)}$ It could be seen that the $\mathrm{N}_{2}$ adsorption capacity increased with increases in the relative pressure below the $p / p_{0}=0.7$ region and formed a thin hysteresis, which could be related to the $\mathrm{N}_{2}$ adsorption on the inside surface of mesoporous channels. In the relative pressure range $0.7<p / p_{0}<1$, the $\mathrm{N}_{2}$ sorption isotherms of $\mathrm{TiO}_{2}$ powders showed a strong hysteresis with a steep rise in the adsorption region, which is associated with capillary condensation of mesoporous channels.

Testing showed the BET surface area of nonhydrolytic $\mathrm{TiO}_{2}$ powders to be $39 \mathrm{~m}^{2} / \mathrm{g}$, the average $\mathrm{BJH}$ pore diameter of the desorption branch of the isotherm to be about $11 \mathrm{~nm}$, and the total pore volume to be $0.012 \mathrm{~cm}^{3} / \mathrm{g}$. All these data clearly confirmed that the as-prepared $\mathrm{TiO}_{2}$ powders possessed a mesoporous structure that may be favorable for enhancing the reduction nitridation of $\mathrm{TiO}_{2}$ powders.

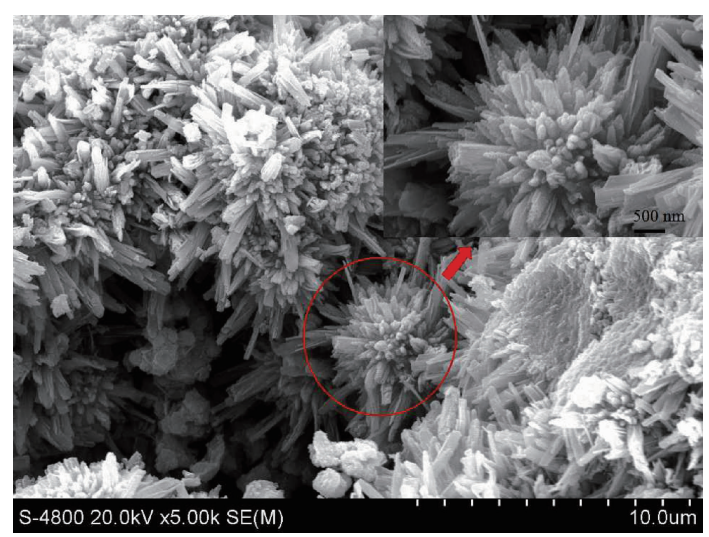

Fig. 2. SEM images of as-prepared $\mathrm{TiO}_{2}$ powders. 

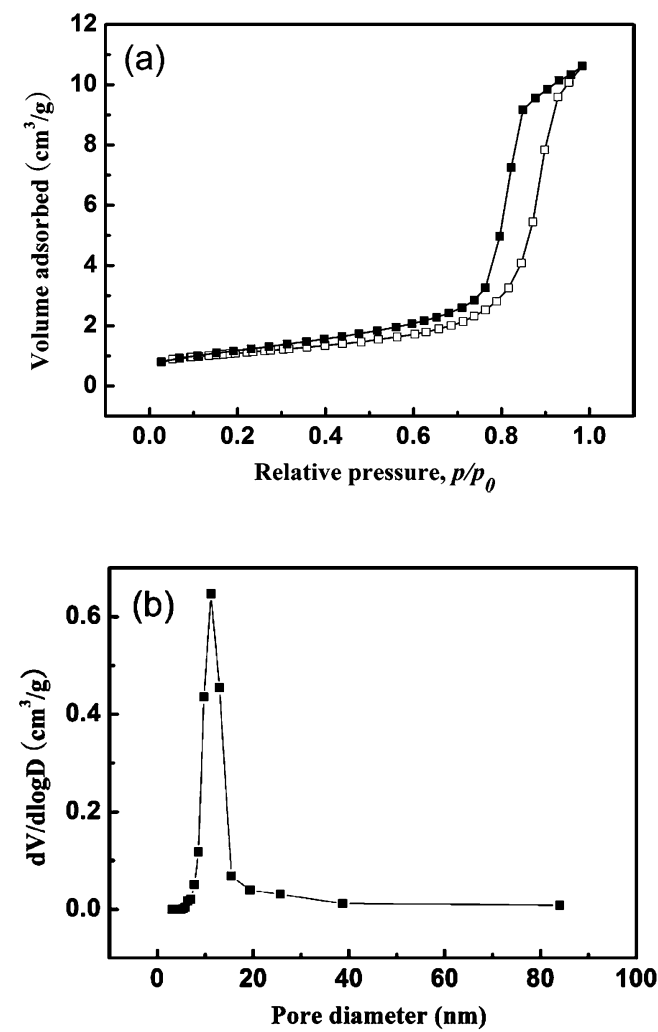

Fig. 3. (a) $\mathrm{N}_{2}$ adsorption-desorption isotherms of as-prepared $\mathrm{TiO}_{2}$ powders and (b) the pore diameter distribution obtained from the desorption branch of the isotherm using the $\mathrm{BJH}$ method.
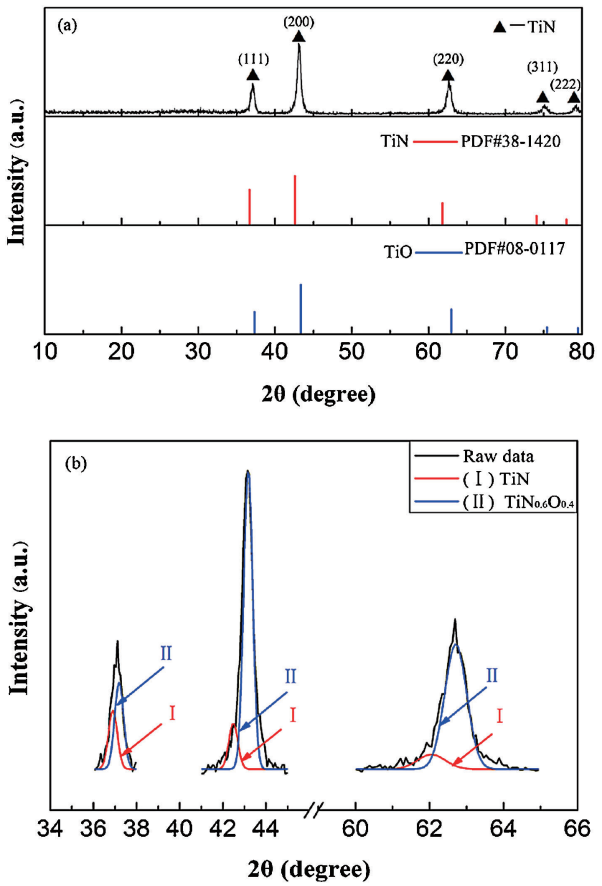

Fig. 4. (a) XRD patterns of TiN powders and (b) muti-peak Guassian fitting results of (111), (200) and (220) XRD lines of TiN powders.

\subsection{Characterization of porous tubular TiN powders}

Figure 4 shows the XRD patterns of the TiN powder samples after reduction nitridation of nonhydrolytic $\mathrm{TiO}_{2}$ powders at

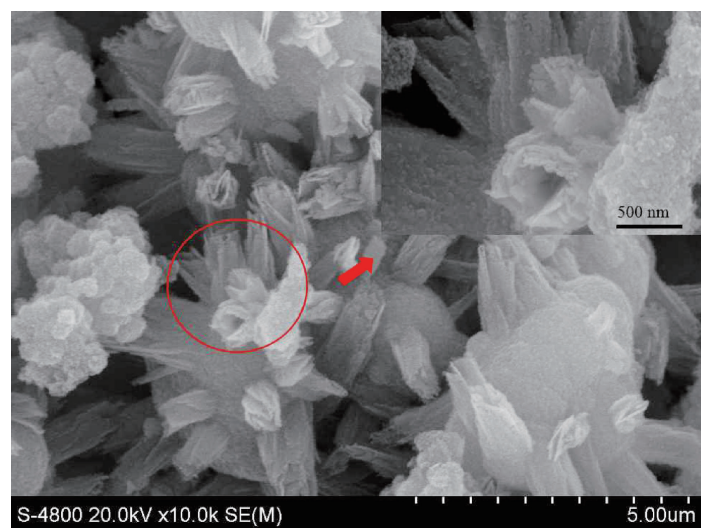

Fig. 5. SEM images of TiN powders.

$800^{\circ} \mathrm{C}$ for $2 \mathrm{~h}$. As shown in Fig. 4(a), the results showed that the diffraction peaks of the nitridation product did not exactly match the cubic TiN corresponding to the (111), (200), (220), (311) and (222) plane reflections. However, the peaks of the (111), (200) and (220) planes showed a broad pattern in the absence of shoulder-peaks. It is indicated that the obtained phases are not of truly pure $\mathrm{TiN}$ but of a titanium oxynitride $\left(\mathrm{TiN}_{1-x} \mathrm{O}_{x}\right)$ with a face-centered cubic arrangement of atoms ( $\mathrm{NaCl}$ structural type) similar to the TiN structure. Therefore, muti-peak Guassian fitting processing of (111), (200) and (220) XRD lines is shown in Fig. 4(b). The results indicate that a part of the TiN-TiO solid solution corresponding to $\mathrm{TiN}_{0.6} \mathrm{O}_{0.4}$ (PDF card No. 49-1325) is formed in addition to the stoichiometric TiN phase. ${ }^{28)}$ The lattice constant of the TiN sample calculated from the XRD patterns was $4.193 \AA$, moreover, which was smaller than the value of the stroichiometric TiN (4.2417 $\AA$ from PDF card No. 38-1420). And the chemical compositions of $\operatorname{TiN}_{1-x} \mathrm{O}_{x}$ were calculated as $\mathrm{TiN}_{0.71} \mathrm{O}_{0.29}$. For reasons of convenience, the nitridation product is still called "TiN". ${ }^{29)}$ The chemical molecular of $\mathrm{TiN}_{1-x} \mathrm{O}_{x}$ was determined using the following formula: ${ }^{30)}$

$$
x=(\alpha-4.175 \AA) /(4.238 \AA-4.175 \AA)
$$

The overall ammonia reduction nitridation reaction can be described as follows:

$$
\mathrm{TiO}_{2}+4 / 3 \mathrm{NH}_{3} \rightarrow \mathrm{TiN}+2 \mathrm{H}_{2} \mathrm{O}+1 / 6 \mathrm{~N}_{2}
$$

The formation and intermediate products of TiN through ammonia reduction nitridation of the as-prepared $\mathrm{TiO}_{2}$ have been suggested to proceed by the following reactions: ${ }^{31)}$

$$
\begin{aligned}
& \mathrm{NH}_{3} \rightarrow 1 / 2 \mathrm{~N}_{2}+3 / 2 \mathrm{H}_{2} \\
& 2 \mathrm{TiO}_{2}+\mathrm{H}_{2} \rightarrow \mathrm{Ti}_{2} \mathrm{O}_{3}+\mathrm{H}_{2} \mathrm{O} \\
& \mathrm{TiO}_{2}+\mathrm{H}_{2} \rightarrow \mathrm{TiO}+\mathrm{H}_{2} \mathrm{O} \\
& \mathrm{Ti}_{2} \mathrm{O}_{3}+\mathrm{NH}_{3} \rightarrow 2 \mathrm{TiN}+3 \mathrm{H}_{2} \mathrm{O} \\
& 2 \mathrm{TiO}+2 \mathrm{NH}_{3} \rightarrow 2 \mathrm{TiN}+2 \mathrm{H}_{2} \mathrm{O}+\mathrm{H}_{2}
\end{aligned}
$$

The morphological structures of the TiN powder samples were observed as shown in Fig. 5. The morphological structures of TiN powders are consistent with those of porous tubular $\mathrm{TiO}_{2}$ powders before reduction nitridation treatment (Fig. 2). This could be explained by suggesting that $\mathrm{O}$ oxygen atoms of the $\mathrm{O}-\mathrm{Ti}$ bonding of $\mathrm{TiO}_{2}$ are gradually displaced in situ with $\mathrm{N}$ nitrogen atoms of $\mathrm{NH}_{3}$ during the reduction nitridation process, and thus the morphological structures of porous tubular $\mathrm{TiO}_{2}$ powders are maintained. ${ }^{32)}$ Porous tubular TiN powders present a layered outer wall structure, moreover, with an average inner diameter of about $440 \mathrm{~nm}$ and length of above $1.2 \mu \mathrm{m}$. 

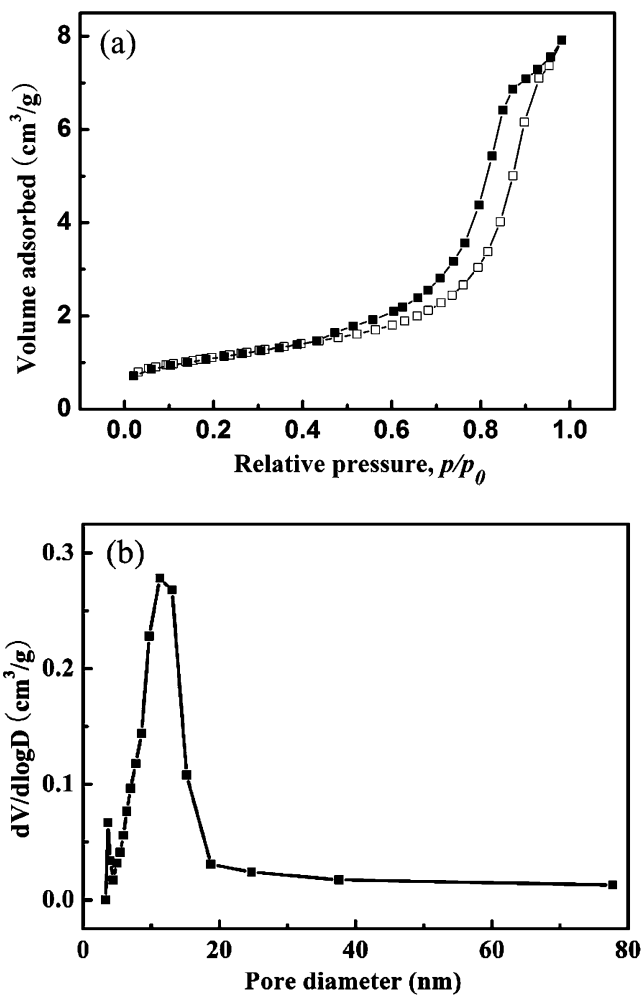

Fig. 6. (a) $\mathrm{N}_{2}$ adsorption-desorption isotherms of TiN powders and (b) the pore diameter distribution obtained from the desorption branch of the isotherm using BJH method.

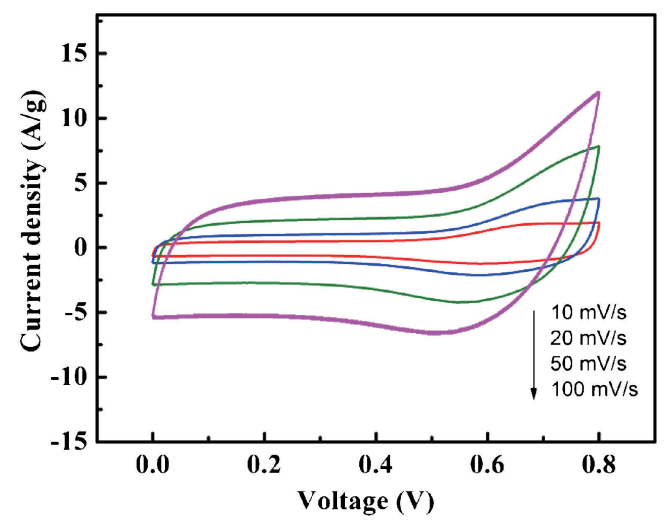

Fig. 7. CV curves of TiN powders (scan rate: $10-100 \mathrm{mV} / \mathrm{s}$ )

The porosity characteristics of the tubular TiN powder samples were determined by $\mathrm{N}_{2}$ adsorption-desorption measurement as shown in Fig. 6. The adsorption and desorption isotherms of the TiN samples showed a Type IV isotherm above the $p / p_{0}=$ 0.45 region. The TiN powders still maintained the characteristics of typical mesoporous structures of tubular $\mathrm{TiO}_{2}$ samples after the reduction nitridation treatment in $\mathrm{NH}_{3}$. $\mathrm{BJH}$ analyses of the desorption branch of the isotherm for the tubular TiN powders exhibited a mean pore diameter of $12 \mathrm{~nm}$, a BET specific surface area of $35 \mathrm{~m}^{2} / \mathrm{g}$, and a pore volume of $0.096 \mathrm{~cm}^{3} / \mathrm{g}$.

\subsection{Electrochemical measurements of porous tubular TiN powders}

$\mathrm{CV}$ tests were carried out to estimate the electrochemical properties of the porous tubular TiN powder electrodes at different scan rates of 10, 20, 50, and $100 \mathrm{mV} / \mathrm{s}$. As shown in Fig. 7,

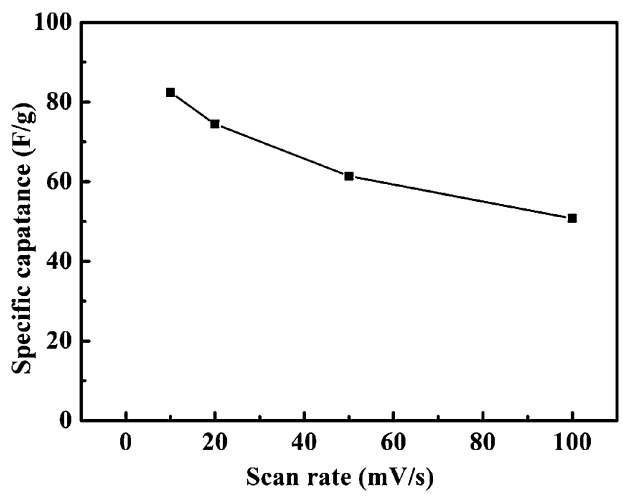

Fig. 8. Specific capacitance curves of TiN powders (scan rate: 10-100 $\mathrm{mV} / \mathrm{s})$.

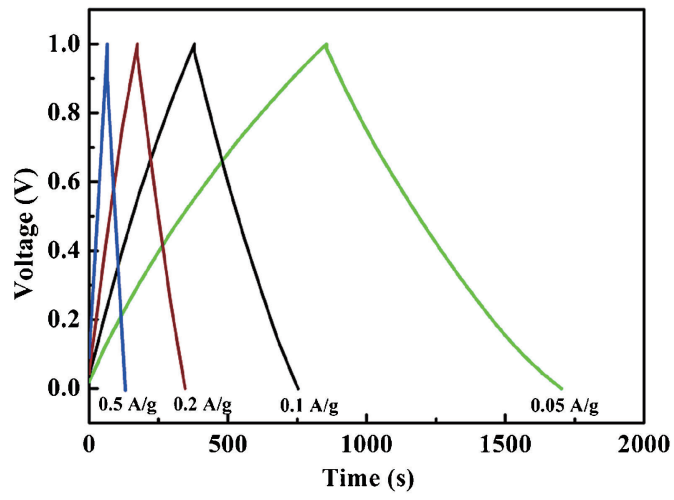

Fig. 9. Charge/discharge curves of TiN powders (current density: $0.05-0.5 \mathrm{~A} / \mathrm{g})$.

with increases in the scan rate, the $\mathrm{CV}$ curves were all estimated to be rectangle-like shapes reflecting the ideal capacitive behavior of TiN. It is indicated that the behavior of porous tubular TiN powder electrodes resembles the response representative of typical electric double-layer capacitors. However, an increase in current between 0.4 and $0.8 \mathrm{~V}$ shows the presence of a redox reaction of TiN in Fig. 7. Hence, the capacitance of the porous tubular TiN powders was attributed to a combination of an electric double-layer capacitor and pseudocapacitance through a faradaic reaction. ${ }^{33)}$ The charge storage mechanism could be based on continuous chemisorption of $\mathrm{Na}^{+}$in the applied potential range, according to the following reaction process:

$$
(\mathrm{TiN})_{\text {surface }}+\mathrm{Na}^{+}+\mathrm{e}^{-} \rightarrow\left(\mathrm{TiN}^{-} \mathrm{Na}^{+}\right)_{\text {surface }}
$$

The specific capacitance of the TiN is calculated by the below equation:

$$
C=\frac{\int_{V_{1}}^{V_{2}} I d V}{m \cdot v \cdot\left(V_{2}-V_{1}\right)}
$$

Where $m$ is the mass of the active material, and $I, v,\left(V_{2}-V_{1}\right)$ are the average current of charge and discharge, scan rate, and potential difference, respectively. The overall specific capacitances of the porous tubular TiN at progressive scan rates (10$100 \mathrm{mV} / \mathrm{s}$ ) were tested as shown in Fig. 8. The highest specific capacitance of the TiN electrode was shown to be $82.4 \mathrm{~F} / \mathrm{g}$ at a scan rate of $10 \mathrm{mV} / \mathrm{s}$. With an increase in the scan rate, the corresponding specific capacitance retention of porous tubular TiN electrodes was $62 \%$. 


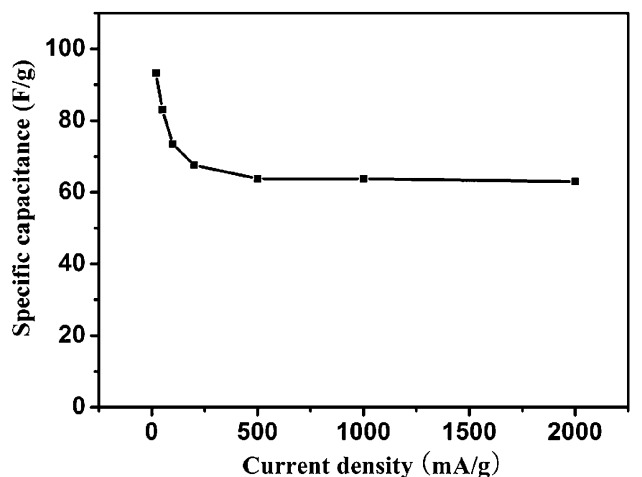

Fig. 10. Specific capacitance curves of TiN powders (current density: $0.05-0.5 \mathrm{~A} / \mathrm{g}$ ).

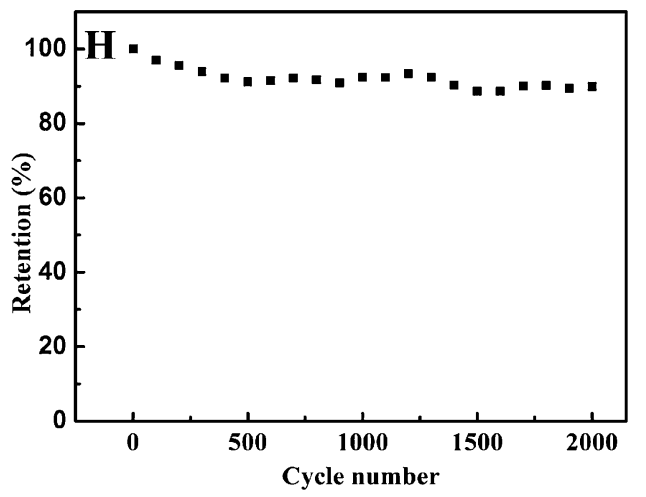

Fig. 11. Cycling performance of TiN powders at a current density of $0.5 \mathrm{~A} / \mathrm{g}$.

The GCD curves of porous tubular TiN powder electrodes in the range of $0.05-0.5 \mathrm{~A} / \mathrm{g}$ are shown in Fig. 9. It can be clearly seen that the GCD curves of the TiN electrode present a good symmetry, indicating good electrochemical reversibility of the TiN electrode material. The charge/discharge times were prolonged with a decrease in the charge/discharge current density. This suggests that the porous tubular structure of TiN electrodes allows rapid ion diffusion and presents an excellent rate capability. The values of the specific capacitance of the porous tubular TiN powders as a function of charge/discharge current density are depicted in Fig. 10. The specific capacitance gradually decreased from 83.4 to $63.8 \mathrm{~F} / \mathrm{g}$ as the current density increased from 0.05 to $0.5 \mathrm{~A} / \mathrm{g}$, indicating a capacity retention of $77 \%$. This indicates that the specific capacitance is inversely proportional to the charge/ discharge current density. It is considered that the decrease in capacitance can be attributed mainly to a relationship in which the higher the current density, the shorter the formed time of the electric double-layer capacitor, a result of the difficulty of electrolyte invasion into micropores of the porous tubular TiN powders.

The electrochemical stability of porous tubular TiN powder electrodes at a current density of $0.5 \mathrm{~A} / \mathrm{g}$ is shown in Fig. 11. It can be seen that a capacity retention of about $92 \%$ is exhibited after 1000 cycles, indicating an ability of TiN powder electrodes to maintain an acceptable cycle. This suggests that there is little electrochemical dissolution or structural collapse of the porous tubular TiN powder electrodes during continuous GCD processes.

EIS was used to investigate the resistance changes in porous tubular TiN electrodes. The Nyquist plot is shown in Fig. 12. A

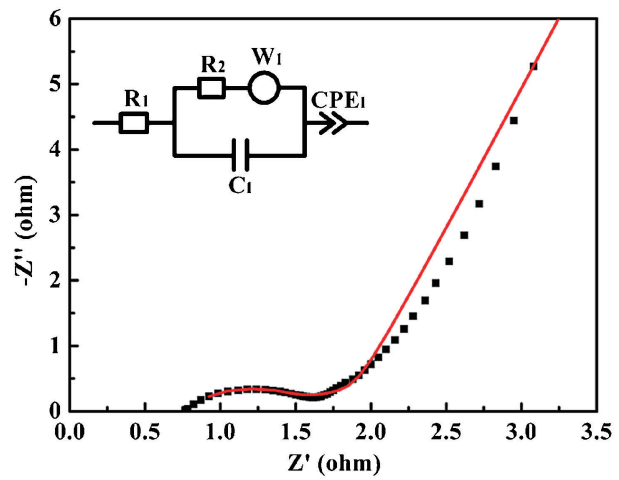

Fig. 12. Nyquist plot of a TiN powder electrode.

depressed semicircle in the middle and a high-frequency region were observed. The internal resistance of the porous tubular TiN electrode was $0.9 \Omega$, a result corresponding to the point intersection with the real axis in the high-frequency range. At low frequencies, the straight line had a finite slope near $45^{\circ}$, which implies diffusive behavior of electrolytes in the pores of the porous tubular TiN electrode. The pore structure characteristic of tubular TiN powders might therefore promote adsorption of $\mathrm{Na}^{+}$ from $\mathrm{Na}_{2} \mathrm{SO}_{4}$ electrolytes. The tubular structure and pores on the walls of TiN electrodes would thus promote rapid ion diffusion and/or possible contributions of electrochemical supercapacitors.

\section{Conclusions}

In conclusion, we have synthesized porous tubular TiN powders via ammonia reduction nitridation of nonhydrolytic $\mathrm{TiO}_{2}$ powders. Using anhydrous ethanol as an oxygen donor, nonhydrolytic porous tubular $\mathrm{TiO}_{2}$ was transformed directly into porous tubular $\mathrm{TiN}$ at high temperature in an $\mathrm{NH}_{3}$ atmosphere. The synthesis of TiN powders was achieved without an external template. And the accessible porous tubular structures of TiN powders contributed to good electrochemical performance of the TiN electrodes. The specific capacitance of the TiN electrodes was $83.4 \mathrm{~F} / \mathrm{g}$ at a current density of $0.5 \mathrm{~A} / \mathrm{g}$. The capacity retention was maintained at $77 \%$ at different current densities. The internal resistance was only $0.9 \Omega$. Furthermore, the results indicate that porous tubular TiN materials could potentially be beneficial for application in supercapacitors.

Acknowledgments The authors are grateful to the National Natural Science Foundation of China (51272066) and Natural Science Foundation of Hebei Province (E2013209183) for their financial support.

\section{References}

1) H. O. Pierson, "Handbook of Refractory Carbides and Nitrides", Ed. by R. F. Bunshah, G. E. McGuire, S. M. Rossngel, Noyes Publications, Park Ridge, NJ (1996) pp. 181185.

2) A. Fischer, P. Makowski, J. O. Muller, M. Antonietti, A. Thomas and F. Goettmann, ChemSusChem, 1, 444-449 (2008).

3) S. Kaskel, K. Schlichte and T. Kratzke, J. Mol. Catal. A-Chem., 208, 291-298 (2004).

4) J. J. He, M. P. Jennifer and Y. B. Cheng, J. Phys. Chem. C, 118, 16818-16824 (2014).

5) C. P. Lee, L. Y. Lin, R. Vittal and K. C. Ho, J. Power Sources, 196, 1665-1670 (2011).

6) X. Y. Zhang, X. Chen, S. M. Dong, Z. H. Liu, X. H. Zhou, J. H. Y. S. Pang, H. X. Xu, Z. Y. Zhang, L. F. Li and G. L. Cui, 
J. Mater. Chem., 22, 6067-6071 (2012).

7) D. Wang, S. Karato and Z. Jiang, J. Mater. Chem., 13, 14961499 (2003).

8) B. Avasarala and P. Haldar, Int. J. Hydrogen Energ., 36, 39653974 (2011).

9) S. Y. Huang, P. Ganesan, H. Y. Jung and B. N. Popov, J. Power Sour., 198, 23-29 (2012).

10) J. M. Lee, S. B. Han, Y. J. Song, J. Y. Kim, B. Roh, I. H. Wang, W. Choi and K. W. Park, Appl. Catal., A-Gen., 1, 149-155 (2010).

11) K. Kakinuma, Y. Wakasugi, M. Uchida, T. Kamino, H. Uchida and M. Watanabe, Electroanal. Chem., 79, 399-403 (2011).

12) M. M. Ottakam Thotiyl, T. Ravi Kumar and S. Sampath, J. Phys. Chem. C, 114, 17934-17941 (2010).

13) S. M. Dong, X. Chen, L. Gu, X. H. Zhou, L. F. Li, Z. H. Liu, P. X. Han, H. X. Xu, J. H. Yao, H. B. Wang, X. Y. Zhang, C. Q. Shang, G. L. Cui and L. Q. Chen, Energy Environ. Sci., 4, 3502-3508 (2011).

14) X. H. Zhou, C. Q. Shang and L. Gu, ACS Appl. Mater. Interfaces, 3, 3058-3063 (2011).

15) D. Choi and P. N. Kumta, J. Electrochem. Soc., 153, A2298A2303 (2006).

16) L. Q. Jiang and L. Gao, J. Am. Ceram. Soc., 89, 156-161 (2006).

17) X. Y. Liu, Y. H. Zhang and T. Wu, Chem. Commun., 48, 99929994 (2012).

18) Y. B. Xie and X. Q. Fang, Electrochim. Acta., 120, 273-283 (2014).

19) G. Hasegawa, T. Sato, K. Kanamori, K. Nakano, T. Yajima, Y. Kobayashi, H. Kageyama, T. Abe and K. Nakanishi, J. Chem.
Mater, 25, 3504-3512 (2013).

20) A. A. Ismailand and D. W. Bahnemann, J. Mater. Chem., 21, 11686-11707 (2011).

21) B. Bruno, G. N. Ranjith and S. K. Sanjoy, New J. Chem., 36, 2196-2200 (2012).

22) C. Wang, Z. X. Deng, G. H. Zhang, S. S. Fan and Y. D. Li, Powder Technol., 125, 39-44 (2002).

23) C. Wang, Z. X. Deng and Y. D. Li, Inorg. Chem., 40, 52105214 (2001).

24) P. Arnal, R. J. P. Corriu, D. Leclercq, P. H. Mutin and A. Vioux, J. Mater. Chem., 6, 1925-1932 (1996).

25) K. M. Doxse, R. C. Chang and E. Chen, J. Am. Chem. Soc., 120, 585-586 (1998).

26) K. S. W. Sing, D. H. Ererett and R. A. W. Haul, Pure Appl. Chem., 57, 603-619 (1985).

27) M. Sugioka and T. Kurosaka, J. Jpn. Petrol. Inst., 45, 342-354 (2002).

28) S. M. Dong, X. Chen, L. Gu, X. H. Zhou, H. X. Xu, H. B. Wang, Z. H. Liu, P. X. Han, J. H. Yao, L. Wang, G. L. Cui and L. Q. Chen, ACS Appl. Mater. Interfaces, 3, 93-98 (2011).

29) S. Schlienger, O. Ersen, L. Roiban and J. Parmentier, J. Am. Chem. Soc., 94, 4142-4145 (2011).

30) H. Y. Wei, M. M. Wu, Z. L. Dong, Y. Chen, J. L. Bu, J. Lin, Y. Yu, Y. N. Wei and R. S. Wang, J. Raman Spectrosc., 48, 578585 (2017).

31) K. Kohno, Mater. Sci., 27, 658-660 (1992).

32) M. H. Chan and F. H. Lu, Thin Solid Films, 518, 1369-1372 (2009).

33) D. Choi and P. N. Kumta, J. Electrochem. Soc., 153, A2298A2303 (2006). 